\section{Boundary practices at incident sites}

\section{Boundary practices at incident sites}

\section{Making distinctions between emergency personnel and the public}

\author{
Linda Kvarnlöf and Roine Johansson \\ Department of Social Sciences, Mid Sweden University, Östersund, Sweden
}

65

Received 31 January 2013 Revised 23 June 2013 Accepted 22 July 2013

\begin{abstract}
Purpose - Incident sites can be described as the joint work site of the emergency services, where one of their challenges is to interact with the public. The purpose of this paper is to study how this interaction is structured by the emergency personnel's jurisdictional claims.

Design/methodology/approach - This paper rests upon qualitative method and in-depth interviews. In total, 28 people have been interviewed, out of which 13 are emergency personnel and 15 are unaffiliated volunteers. The interview material has been analysed qualitatively and thematically by the authors.

Findings - The findings show that the interaction between emergency personnel and unaffiliated volunteers can be described in terms of three different boundary practices: cordoning off, division of labour and conversation, varying in degrees of inclusion and exclusion. The result shows that the emergency personnel's relationship to volunteers is ambivalent, as they are both seen as an uncertain element at the incident site in need of control and as a valuable source of information.

Originality/value - While most other studies have been focusing on the interaction between emergency organizations, the authors have investigated the interaction between emergency organizations and a group previously unstudied: unaffiliated volunteers. While sociologists in the field of boundary work normally describe boundary practices in terms of negotiation, sympathizing with the concept of negotiated order, the results point to the fact that boundaries are not necessarily a subject for negotiation.
\end{abstract}

Keywords Emergency services, Boundary work, Incident sites, Occupational jurisdictions, Traffic accidents, Unaffiliated volunteers

Paper type Research paper

\section{Introduction}

Practitioners and researchers alike emphasize the need for collaboration between the emergency services and the public during emergencies. It is argued that such collaboration would make the emergency response more effective, and that the public could make a great contribution given that the resources of the emergency services are necessarily limited. However, the emergency services have been described as a complex environment to manage (Wankhade and Murphy, 2012), not least when it comes to their public relations. Emergency personnel are responsible for both protecting and saving the public from danger, and cooperating with the public in emergency response activities. The relationship of the emergency personnel with the public has been described as highly complicated, with the public seen as being a "mixed blessing" (Barsky et al., 2007): a possible source of

This work was financially supported by the Swedish Civil Contingencies Agency, which is gratefully acknowledged. The authors would like to acknowledge their colleagues at the Risk and Crisis Research Center and the Department of Social Sciences at the Mid Sweden University for helpful comments on earlier drafts of this manuscript.

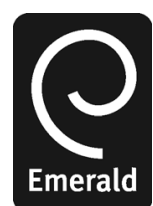

International Journal of Emergency Services

Vol. 3 No. 1,2014 pp. $65-76$

(C) Emerald Group Publishing Limited 2047-0894 
IJES

3,1

66 assistance and information on the one hand, yet a potential hindrance in the emergency response on the other.

In this paper, we will take a closer look at the interaction between emergency personnel and the public at road traffic accidents. More specifically, the public will be studied in their role as organizationally unaffiliated volunteers, i.e. individuals who happen to arrive first at an incident site. These people are volunteers since they, more than just staying at the incident site, take some action in order to help the victims of the accidents, for example, by calling the emergency call center or by caring for the victims by giving them first aid. More so, these volunteers have stayed at the incident site in order to meet up with the emergency personnel. We will analyse the interaction between emergency personnel and volunteers in terms of boundary work and boundary practices, referring to the practices whereby professionals distinguish themselves from lay people (Gieryn, 1983; Yan and Louis, 1999; Fournier, 2000). While previous research has shown how boundary work is used by professionals to claim exclusivity and control over a particular practice (Gieryn, 1983; Macdonald, 1995; Fournier, 2000), here we will show how the interaction between the public and emergency personnel is characterized by the latter's boundary practices.

The interaction between emergency personnel and unaffiliated volunteers has been studied at a specific interactional setting: the incident site. As the emergency personnel's joint place of work, this can be described in terms of what Abbott (1988) calls heteronomous worksites - sites that bring members of related professions together. Abbott describes worksites as one of several possible arenas for jurisdictional claims. The incident site can be described as an arena where the emergency personnel claim both legal and public authority. It is their home ground, an arena for professional claims, where unaffiliated volunteers are only temporarily welcome.

Although a highly institutionalized place, the incident site is associated with a high degree of uncertainty. Since it is impossible for emergency crews to know when or where their next place of work will be established (their workplace is constructed whenever and wherever an accident has occurred), the incident site can be said to be characterized by both temporal and spatial uncertainty. Social uncertainty too, not least when it comes to the presence of unaffiliated volunteers: emergency personnel do not know whom they will meet at the incident site, nor do they know the competences of those already there. When one incident site is never like the next, when the emergency personnel constantly interact with new people and new places, it is likely that the need for control and management will increase. In times of uncertainty, the need for routines and professional claims becomes even greater.

The aim of this paper is to study how the interaction between unaffiliated volunteers and emergency personnel is structured by the latter's jurisdictional claims. More specifically, we will study jurisdictional claims as a form of boundary practice by which emergency personnel distinguish themselves from unaffiliated volunteers. We will show how boundary practices serve to construct a workplace just as much as to establish professional legitimacy.

\section{Boundary work and boundary practices}

Being the first to introduce the expression boundary work, Gieryn (1983) studied the academic use of discursive practices in separating scientific knowledge from common knowledge. By constructing boundaries between science and non-science, scientists distinguished themselves from "the public" in order to claim intellectual authority. At their most effective, these boundaries were constructed and reconstructed in a way that set scientific knowledge apart in the most favourable way in a given situation. 
From the concept of boundary work it can be argued that professionalization is accomplished through the construction of boundaries. For example, Gieryn (1983) determined that one of the purposes of boundary work was monopolization, where professionals claim sole right to a profession or practice by dint of excluding rivals, categorizing them as "outsiders" or "amateurs". In a similar vein, although writing in terms of jurisdictions rather than boundaries, Abbott (1988) argues that professionals distinguish themselves and their profession through occupational jurisdictions. However, Abbott argues that, more than just claiming authority, professionals construct boundaries in order to claim exclusivity and control over a particular practice.

Again according to Abbott (1988), jurisdictional claims can be made in several possible arenas, and he emphasizes the workplace as an important arena for occupational jurisdictions. In the workplace, jurisdictions serve as a way to control the work and its associated tasks. As Abbott points out, there is usually little debate about what needs to be done; however, the division of labour in terms of who needs to do what is very much a subject for jurisdiction. In professional work settings, divisions of labour are established "through negotiation and custom, that embody situation-specific rules of professional jurisdiction" (Abbott, 1988, p. 65). In the present paper we will describe the division of labour as one of several boundary practices at the incident site; a boundary practice by which the emergency personnel control the presence of unaffiliated volunteers.

In this paper we will show how occupational jurisdictions are protected through boundary practices, distinguishing insiders from outsiders. Drawing on the concept of boundary work presented by Nippert-Eng (1996), boundary practices can be described as the "doing" part of boundary work - as the practices we use to distinguish different cultural categories from one another. While Nippert-Eng describes boundaries as being mainly cognitive, and boundary practices as being mainly a mental activity, we hold boundaries and boundary work to be social processes. Far from being constructed in “one's head”, boundaries are constructed in the social interaction with others.

Moreover, boundaries are not necessarily rigid; rather, they are more or less permeable, readily crossed, and rather than being stable, their structures are flexible and change over time. As Nippert-Eng (1996) argues, boundaries are repeatedly drawn and redrawn to include and exclude, and sometimes even to re-include, a variety of elements. We will show how boundary practices not only concern the placement of boundaries, but are just as much about their maintenance and displacement.

Boundaries come in a variety of forms. They can be external as well as internal, material or spatial, symbolical or social. Since we are interested in the distinction between professionals and lay people, social boundaries are the order of the day. Social boundaries refer to practices by which groups and individuals are separated from one another and categorized (Gieryn, 1983; Logan et al., 1996; Lamont and Molnár, 2002). For example, social boundaries have been studied in terms of distinguishing between people by class (Massey, 1990), gender (Lamont and Molnár, 2002), and ethnicity (Logan et al., 1996); between experts and the public (Gieryn, 1983); or between professionals and clients (Fournier, 2000; Malin, 2000). Even material or spatial boundaries are social in their consequences, for example, when cordoning off the incident site. Even though it is material in nature, and it does not take much effort to cross-caution tape or drive past an officer on guard, because it comes with well-established cultural norms it is very seldom crossed. The public show respect for the cordon, not because of its materiality, but because of its symbolic value.

\section{Boundary practices at incident sites}


IJES

3,1

68

\section{A critique of negotiation in boundary work}

In previous studies, the interactive aspect of boundary work has been studied in terms of negotiation (Nippert-Eng, 1996; Allen, 2000). According to Nippert-Eng (1996), boundaries are negotiated as we enact, reinforce, and modify our ideas of different cultural categories. Inspired by Strauss's (1978) concept of negotiated order, Allen (2000) argues that work identities and occupational margins are negotiated, and continues that it is not only the work's identity that is a product of negotiation: from a negotiated order perspective, this applies to the organizational structure as well. According to Glaser and Strauss (1964), even structures are negotiated orders, rather than pre-determined, fixed ones.

However, and with reason, there are objections to this rather structureless perspective. Strauss's critics have repeatedly argued that the negotiated order perspective pays all too little attention to limitations on actors' freedom of action (see Day and Day, 1977). Not everything in an organization can be negotiated. When even organizational structures are described as being negotiated (Glaser and Strauss, 1964), suddenly "everything" becomes a question of negotiation. This could be described as a simplification or "structure-blindness", and critics (see Dingwall and Strong, 1997) have singled out this turn in organizational studies as one that now overemphasizes negotiation at the cost of formal organizational structure, thereby inverting the original problem.

Other researchers have emphasized the controlling aspect of boundaries (Gieryn, 1983; Zerubavel, 1991) and boundary work (Abbott, 1988; Macdonald, 1995; Perlow, 1998). In studies of the distinction between professionals and lay people, it has been shown that boundaries are constructed in order to claim exclusivity and control (see Gieryn, 1983; Macdonald, 1995). Hence, boundary work, as we see it, covers more than negotiation, and needs to be understood in relation to its structural context. True, boundary work can sometimes take place through negotiation, but - as we will show here - it can also proceed in other ways. When studying the boundary work evident in the distinction between emergency personnel and unaffiliated volunteers at an incident site, any attempt to describe it in terms of negotiation becomes even more problematic, since boundary work is not studied within an organization. Emergency personnel - as representatives of organizations - have access to organizational resources that generate professional legitimacy and authority, whereas volunteers represent only themselves. In that sense, the power relationship between professionals and unaffiliated volunteers is highly asymmetric. Due to the high degree of institutionalization, the authority of the emergency personnel is rarely questioned by anyone present, and the allocation of roles and assignments is not subject to negotiation. Hence, the boundary work at the incident site is more likely practiced through control and instruction than by negotiation.

\section{Method}

This paper is based upon two parallel interview studies, one with emergency personnel and one with unaffiliated volunteers. The interviews with emergency personnel focus on questions of their profession, their professional practice, and their encounters with the public as a part of this professional practice. While the interviews with emergency personnel are based on a more general understanding of emergency management, the interviews with unaffiliated volunteers can be described as "situated narratives" (Wood, 1992; Wirth and Gamon, 1999), focusing on their experiences of being first on site at specific traffic accidents. More so, the volunteers were asked to describe their experience of their encounter with emergency personnel at the incident sites. 
In total, the empirical material consists of 25 in-depth interviews with 13 professionals (four police officers, four fire-fighters, five paramedics) and 15 unaffiliated volunteers. With a few exceptions (paramedics 2 and 3, paramedics 4 and 5, unaffiliated volunteers 9 and 10), the material consists of individual interviews. However, when the interviewees asked to do the interview in pairs, we let them do so. In this paper material from the interviews with emergency personnel are overrepresented in relation to material from the interviews with volunteers. However, this goes in line with the aim of this paper, as it is the emergency personnel who perform the boundary practices and it is their boundary work which is the main focus of this paper. If the voices of the emergency personnel are to exemplify the way that they distinguish their profession at the incident site through boundary practices, the voices of the volunteers are to exemplify how these distinctions are experienced from the outside. In combination, they represent two sides of the boundary practices at incident sites, the ones who are included through boundary practices and the ones who (most often) are not. The emergency personnel represented here are drawn from the so-called "blue light services". Our interviewees are operational personnel from the fire and rescue services, police officers, and ambulance crews who manage emergencies such as road traffic accidents as a part of their daily work. While differences in approach to the public according to the organizational affiliation of the emergency personnel have been subject of research elsewhere (Johansson, 2013), here we will focus on the similarities based on the emergency personnel's shared professional presence: they share the incident site as a common place of work, and even though they have different tasks and responsibilities, they share the priority and task of saving lives and property.

The sample of unaffiliated volunteers can best be described as situated, since they have been chosen for their situational rather than personal characteristics. The interviewees are sampled according to the traffic accidents they have witnessed. These were traffic accidents of the highest priority, meaning that at least one person is in need of medical care and that the ambulance and fire and rescue services are ordered to get to the incident site at quickly as possible. All traffic accidents occurred in rural areas and none of them had fatal consequences. Moreover, all the interviewees have that in common that they arrived at the incident site before the emergency personnel, and that they waited for the arrival of the emergency personnel. The unaffiliated volunteers were registered as witnesses by the police or as having telephoned the emergency services, and we came into contact with them with the assistance of the police and the emergency call centres.

The interview material has been analysed qualitatively and thematically by the authors. Our analysis of the material was inspired by theories of boundary work. We have searched the material for practices which enlighten the interaction between emergency personnel and unaffiliated volunteers. However, the boundary practices as such are derived from the empirical material where the three practices (cordoning off, division of labour, conversation) that we account for in this paper are the most distinctive ones. These are practices which give expression for different aspects of the most central theme in the empirical material, namely the construction and management of a workplace.

\section{Boundary practices at incident sites}

An incident site can be described as a heteronomous worksite (Abbott, 1988), since it is a workplace shared by fire-fighters, the police, and ambulance crews. We will consider how occupational jurisdictions are performed through boundary practices,

\section{Boundary practices at incident sites}

69 
IJES

3,1

70

describing the distinction between emergency personnel and unaffiliated volunteers in relation to three different boundary practices: cordoning off, division of labour, and conversation. All three are practiced by the emergency personnel in order to regulate their interaction with volunteers - albeit by exclusionary as well as inclusive strategies - and the result is boundaries that are placed, displaced, and sometimes "just" maintained.

Unlike most other places of work, an incident site is not a "fixed", permanent, location. Rather, it is constructed anew each time an accident happens. An incident site is constructed by the boundary practices of the emergency personnel, through their placement of both social and spatial boundaries. As they cordon off an incident site with vehicles or caution tape, they also mark their territory, or arena (Abbott, 1988), and mark out a space for their jurisdictional claims. As a consequence, the cordon is just as much a social as a spatial boundary, distinguishing who has access to the arena and who does not. In other words, the cordon serves as a way to distinguish between insiders and outsiders.

However, the incident site is not only a place of work; it is just as much an interactional setting. Where cordoning off is primarily about the physical placement of boundaries, the boundary practices of the division of labour and conversation are more interactive and inclusive in nature. It is through the division of labour, when emergency personnel organize the volunteers, that the boundaries that distinguish the two from each other are manifested and maintained. When it comes to conversation, the emergency personnel depend on the unaffiliated volunteers as a source of witness statements and information, and, to some degree, the boundaries that exist between them are displaced in order to include the volunteers.

\section{Cordoning off: placing boundaries}

It is by cordoning off the incident site that the emergency personnel establish their common inter-organizational workplace. Primarily, the space is cordoned off by the placement of spatial boundaries when the emergency personnel mark their territory with parked vehicles or caution tape. Usually, cordoning off an incident site is the responsibility of the police. One of the interviewed police officers describes the main purpose of cordoning off as securing the incident site:

Our first priority when we arrive at the incident site is to secure this place. That's our main task: to protect the incident site. It's really only the fire and rescue services and the ambulance that are allowed in this area (Police officer 2).

"Securing the place" is not only a question of safety; it is as much about constructing the boundaries for belongingness, with only emergency personnel allowed inside the cordon. Hence, even if the practice of cordoning off is initially spatial in character, it becomes social as soon as it manifests occupational jurisdictions and the distinction between emergency personnel and unaffiliated volunteers.

More than being a material and social practice, cordoning off as such has a strong symbolic value. Being highly institutionalized, people tend to respect the cordon and keep out, although it would not take much effort to cross the caution tape if they wanted. People respect the cordon when managed by emergency personnel, and it seems as if the cordon needs organizational legitimacy in order to function properly. Sometimes too properly, one might argue:

I think, many times people are forced into being bystanders. I'm pretty sure about that. When we arrive, it is most likely like that. But it is hard to include them (Police officer 4). 
The police as well as the unaffiliated volunteers describe the difficulties in transcending such a highly institutionalized boundary as the cordon. Indeed, cordoning off on many occasions forces the volunteers to become lookers-on. Initially this is the actual purpose of the cordon and hence the exclusion is not necessarily problematic; however, frequently the exclusion of unaffiliated volunteers is only temporary, for even if at first they are excluded from the site, the emergency personnel may well wish to include them later on. For example, all three emergency organizations want contact with unaffiliated volunteers as sources of information. However, this fact is not always communicated to the volunteers, who, not knowing about the temporary character of the exclusion, might interpret it as absolute:

It felt as if they didn't need me, and I felt that if I'd stayed I would only have been in the way. So we left. But I don't know that for sure. I mean, they could have needed me. That was difficult: "Do they need help?" or do we need too [... Should we get something? (Volunteer 2).

Cordoning off not only serves to differentiate between specific places or different actors; as a boundary practice, it also makes it possible for the emergency personnel to control the presence of unaffiliated volunteers. Forced to become bystanders, the volunteers are impelled into passivity through exclusion. Yet even more so, unaffiliated volunteers are controlled by spatial inclusion. Sometimes cordoning off an incident site ensures that they will stay put:

You put them in, put them in a car. 'Cos sometimes people can be shocked as well and just to get them inside, well to stop them getting cold, but also to get them inside as a way to legitimate their presence. And if they've been put in a car, they don't get out. I guarantee it. Then, sure as hell, they'll stay there until someone opens the door and tells them "It's OK now" (Police officer 2).

As a boundary practice, then, cordoning off can be described as being exclusionary in character as it is primarily about the placement of boundaries. When the emergency personnel establish their place of work and mark their territory by cordoning it off, they also construct an arena, making it possible for them to claim jurisdiction (Abbott, 1988). Even if the incident site is cordoned off by the placement of physical boundaries, such as caution tape or vehicles, because the main purpose of the cordon is to distinguish between insiders and outsiders, these boundaries are truly social in their ramifications. However, there are circumstances when emergency personnel actually wish to keep the unaffiliated volunteers inside the cordon. Thus cordoning off is not necessarily exclusionary; it can also be inclusive as well.

\section{Division of labour: maintaining boundaries}

While cordoning off is mainly about the placement of boundaries, or about the construction of an arena for jurisdictional claims, what then of the division of labour as a boundary practice that manifests and maintains the boundaries between emergency personnel and unaffiliated volunteers? Certainly, division of labour is a central aspect of the collaboration between emergency personnel and volunteers. Here it is used to refer to the boundary practice by which the emergency personnel manage the presence of unaffiliated volunteers - in other words, it does not refer to the division of labour between or within different professions, as studied by for example Abbott (1988).

The need for collaboration between emergency personnel and the public is emphasized in critical situations or when the emergency organizations do not have enough resources. One of the interviewed fire-fighters describes this need for assistance:

Well, as I said before, we might need assistance from the public because we need more hands. If it's a serious accident. And we have to tell them what kind of assistance we need, and we

\section{Boundary practices at incident sites}


IJES

3,1

72 have to set the boundaries. 'Cos we can't have private people running around making decisions on their own. It's up to us to ask them for assistance (Fire-fighter 4).

The inclusion of unaffiliated volunteers is a matter of both division of labour and control. As a boundary practice, division of labour is both inclusive and exclusionary. In order to have the assistance of volunteers, they need to be spatially included. However, even if they are invited inside the spatial boundaries of the incident site in order to assist the emergency personnel, the social boundaries and occupational jurisdictions are still constantly guarded and maintained. Even if the unaffiliated volunteers are included spatially, they are never truly included socially. As shown in the quote above, the spatial inclusion of volunteers places special demands on guarding and maintaining the emergency personnel's boundaries and occupational jurisdictions. As Zerubavel (1991) pointed out, it seems as if boundaries that appear to be threatened increase the need for protective action.

But more so, division of labour makes it possible for the emergency personnel to control the presence of unaffiliated volunteers and to organize them. When emergency personnel need to keep volunteers at a distance, in order to perform their own work without being disturbed, they might use division of labour as a form of distraction:

At the incident site you can ask them to go and get a blanket. Things like that. To keep them busy (Paramedic 1).

"We will take care of this, just stay calm. I want you to do this, and then do that". Give them a task. "And then meet over there and await further instructions." That's what I normally say at traffic accidents (Fire-fighter 3).

In other words, while partly included, unaffiliated volunteers are controlled or organized in a way that distinguishes them from the professionals. Even when spatially included, by being allowed to cross the caution tape, they are socially excluded: the emergency personnel do not really integrate them in the actual rescue work, leaving the volunteers to work alongside the emergency personnel rather than with them.

If cordoning off is mainly about the placement of boundaries, so division of labour is more about maintaining boundaries. Even if division of labour can be described as an example of actual collaboration between emergency personnel and unaffiliated volunteers, it is important to note that this practice is strictly controlled by the emergency personnel. Rather than collaborating, emergency personnel and volunteers work side by side, performing very different tasks. Yet while their practical assistance can be useful, unaffiliated volunteers are indispensable to the emergency organizations because they are often witnesses. We will now move on to the third, and the most inclusive, boundary practice: conversation.

\section{Conversation: displacing boundaries}

As the unaffiliated volunteers have usually witnessed the accidents, they are valuable sources of information for the emergency personnel. Sooner or later they will want to get in contact with the volunteers, a need which is shared by all three organizations:

If there are a group of people standing around the incident site, I always ask around: "What have you seen?" or "Who owns the car?" and so on (Police officer 3).

$[\ldots]$ that they are available when we arrive. Like, quickly telling us what's happened. Because that can be incredibly important. We can have an unconscious patient who's now awake. We can lose so much [information], so that's important (Paramedic 2).

I always try to get some introductory information. Some general information, like what's 
happened. Then I try to get some more information later on. Then I try to take them to one side to get some more information when we've started our operation (Fire-fighter 3).

On most occasions the emergency personnel come in contact with the unaffiliated volunteers only after a while, since their priorities at the incident site are primarily to save lives and property, and only secondarily to investigate the accident. Here we see one drawback of cordoning off: the emergency personnel risk losing volunteers by excluding them from the incident site. As a paramedic puts it:

When it comes to more serious accidents, you don't want the public hanging around. So we ask them to go away. But that also means that we lose their information (Paramedic 3).

However, where cordoning off is mainly about the placement of boundaries, conversation is all the more about the displacement of boundaries. In order to get information and witness statements, the emergency personnel try to include the unaffiliated volunteers. In terms of dependence, when it comes to conversation it is the emergency personnel who depend on the volunteers' information rather than the other way around. However, as a boundary practice, conversation points to the difficulties in displacing boundaries once they have been put in place. It is hard to include people once they have been excluded.

While conversation can be described as a displacement of the social boundaries between emergency personnel and unaffiliated volunteers, a lack of conversation is an equally effective way of exclusion, and maintenance of the incident site boundaries. Since conversation is an important aspect of the working practice at the incident site, to ignore unaffiliated volunteers can have consequences for the emergency response. One of the interviewees describes a situation where she was ignored by a paramedic:

Well, the only thing they asked, or when he saw the helmet lying on the ground, the paramedic said, "Good thing you had your helmet on". And the boy just nods his head. So I had to say, "But he didn't have his helmet on; it came off when he ran into the pole". And he just looked at me, the paramedic. Didn't say a word (Volunteer 5).

This is not only an example of the consequences of ignoring unaffiliated volunteers. It is also an example of the valuable information these people possess; information that is of great importance for the emergency response.

\section{Conclusion}

We have considered examples of three different boundary practices at incident sites: cordoning off, division of labour, and conversation. The boundary practices include aspects of inclusion as well as exclusion, while some are more exclusionary than others. Where cordoning off and division of labour are more exclusionary in nature - serving to place or maintain the boundaries between emergency personnel and unaffiliated volunteers - conversation is mainly inclusive, since the emergency personnel need information from the volunteers in order to carry out a successful emergency response. In this way, boundary practices serve as a valuable analytical tool in order to understand the complexities of integrating and excluding unaffiliated volunteers at incident sites.

It is important to notice that these boundary practices are practiced at the incident site, the workplace of the emergency personnel and an important arena for their jurisdictional claims (Abbott, 1988). The incident site is a heteronomous worksite, where several related professions work together. In this paper, however, all the emergency personnel are regarded as a homogeneous professional group, distinct from

\section{Boundary practices at incident sites}

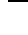


IJES

3,1

74

the unaffiliated volunteers. It is precisely the construction and management of this distinction that has been studied here.

The power relationship between professionals and unaffiliated volunteers is highly asymmetrical, and the boundary work at the incident site is an expression of that asymmetrical power. As a consequence, the legitimacy of the emergency personnel is very seldom questioned, and even more rarely a subject for negotiation. Therefore, it would be misleading to interpret the boundary practices in terms of negotiation, as argued by Nippert-Eng (1996). In the present paper, boundary practices revolve around the legitimacy and initiative of the emergency personnel rather than any negotiation. For example, this is shown by the fact that all boundary work that takes place at the incident site occurs on the initiative of emergency personnel. More than making distinctions between professionals and lay people, boundary practices at the incident site serve as a way of controlling the presence of unaffiliated volunteers by excluding or including them. However, even when boundary practices are inclusive and boundaries to some degree are displaced, they are nevertheless controlled and managed by the emergency personnel - in other words, even if they vary in their degree of inclusion and exclusion, or placement and displacement, a common feature of boundary practices is that they are all managed by the emergency personnel. Therefore, we question the appropriateness of the use of the term "collaboration" when it comes to emergency personnel and the public. The division of labour at the incident site is characterized by control and boundary maintenance. Rather than working together, side by side at the incident site, unaffiliated volunteers are allowed to participate only under the supervision of the emergency personnel.

It is our belief that this paper could make a valuable contribution to both the sociology of boundary work and the field of emergency management research, as it shows both how a number of boundary practices are used in order to establish and maintain a temporary place of work, and how emergency personnel and unaffiliated volunteers interact with each other at incident sites. However, there are points not developed here, which could be subject for future research. For example when it comes to our critique of the negotiating aspect of boundary work we have studied a relationship, the one between emergency personnel and unaffiliated volunteers, that seems unfruitful to analyse in terms of negotiations. This may be the case whenever professionals interact with the public, where the former claims legitimacy and expertise due to their professional and organizational affiliation. However, this needs to be further investigated and applied to other relationships than the one studied in this paper. Another subject for future research is the role of unaffiliated volunteers in times of emergencies. Here, their stories lie in the background, witnessing about the experiences of being excluded at the incident site. In future research their voices need to be brought to the foreground, telling their stories about being first on scene.

When it comes to practical implications, our results point at opportunities of integrating the public in emergency response. First, they are important sources of information, as they often have witnessed the accident. More so, they are important in terms of assistance when the resources of the emergency personnel are scarce. However, these opportunities are surrounded by a possible obstacle, namely the boundary work of the emergency personnel. If the boundary work becomes too rigid it is most likely that the volunteers leave the incident site, because they feel excluded, and the emergency personnel could lose important information. If emergency personnel wish to include unaffiliated volunteers, they need to improve their ways of communicating with these people. 


\section{References}

Abbott, A. (1988), The System of Professions: An Essay on the Division of Expert Labor, University of Chicago Press, Chicago, IL.

Allen, D. (2000), "Doing occupational demarcation - the 'boundary-work' of nurse managers in a district general hospital”, Journal of Contemporary Ethnography, Vol. 29 No. 3, pp. 326-356.

Barsky, L.E., Trainor, J.E., Torres, M.R. and Aguirre, B.E. (2007), "Managing volunteers: FEMA's urban search and rescue programme and interactions with unaffiliated responders in disaster response”, Disasters, Vol. 31 No. 4, pp. 495-507.

Day, R. and Day, J.V. (1977), "Review of current state of negotiated order theory - appreciation and a critique”, Sociological Quarterly, Vol. 18 No. 1, pp. 126-142.

Dingwall, R. and Strong, P.M. (1997), "The interactional study of organizations: a critique and reformulation", in Miller, G. and Dingwall, R. (Eds), Context and Method in Qualitative Research, Sage Ltd, London, pp. 139-155.

Fournier, V. (2000), "Boundary work and the (un)making of the professions", in Malin, N. (Ed.), Professionalism, Boundaries and the Workplace, Routledge, London, pp. 67-86.

Gieryn, T.F. (1983), "Boundary-work and the demarcation of science from non-science: strains and interests in professional ideologies of scientists", American Sociological Review, Vol. 48 No. 6, pp. 781-795.

Glaser, B. and Strauss, A. (1964), "Awareness contexts and social interaction”, American Sociological Review, Vol. 29 No. 5, pp. 669-679.

Johansson, R. (2013), "Professional emergency responders and unorganized volunteers: incident sites as meeting places”, RCR Working Paper Series No. 2013:2, Mid Sweden University, Östersund.

Lamont, M. and Molnár, V. (2002), "The study of boundaries in the social sciences", Annual Review of Sociology, Vol. 28 No. 1, pp. 167-195.

Logan, J.R., Alba, R.D. and Shu-Yin, L. (1996), "Minority access to white suburbs: a multiregional comparison", Social Forces, Vol. 74 No. 1, pp. 851-881.

Macdonald, K.M. (1995), The Sociology of the Professions, SAGE, London.

Malin, N. (2000), Professionalism, boundaries and the workplace, Routledge, London.

Massey, D.S. (1990), "American apartheid - segregation and the making of the underclass", American Journal of Sociology, Vol. 96 No. 2, pp. 329-357.

Nippert-Eng, C. (1996), Home and Work: Negotiating Boundaries Through Everyday Life, University of Chicago Press, Chicago, IL.

Perlow, L.A. (1998), "Boundary control: the social ordering of work and family time in a high-tech corporation", Administrative Science Quarterly, Vol. 43 No. 2, pp. 328-357.

Strauss, A. (1978), Negotiations: Varieties, Contexts, Processes, and Social Order, Jossey-Bass, San Francisco, CA.

Wankhade, P. and Murphy, P. (2012), "Bridging the theory and practice gap in emergency services research: a case for a new journal”, International Journal of Emergency Services, Vol. 1 No. 1, pp. 4-9.

Wirth, D. and Gamon, J. (1999), "The art of situated narrative: a tool to teach environmental ethics", Journal of Vocational Education Research, Vol. 24, pp. 45-61.

Wood, J.T. (1992), "Telling our stories: narratives as a basis for theorizing sexual harassment", Journal of Applied Communication Research, Vol. 20 No. 4, pp. 349-362.

Yan, A.M. and Louis, M.R. (1999), "The migration of organizational functions to the work unit level: buffering, spanning, and bringing up boundaries", Human Relations, Vol. 52 No. 1, pp. 25-47.

\section{Boundary \\ practices at incident sites}



New York, NY.

\section{About the authors}

Linda Kvarnlöf is a $\mathrm{PhD}$ Student in Sociology, writing her thesis about unaffiliated volunteers where she is focusing on their behaviour at incident sites. Her interest of research comes from a research project that started in 2008, funded by the Swedish Civil Contingencies Agency, with the aim to investigate the collaboration between emergency services and volunteers. Since then she has become more and more interested in the behaviour of these unaffiliated volunteers and in which way their actions are structured by the organizational as well as the social context at incident sites. Linda Kvarnlöf is the corresponding author and can be contacted at: linda.kvarnlof@miun.se

Roine Johansson is a Professor of Sociology. His research interests lie mainly within the area of organization studies. He has studied street-level bureaucrats in different public authorities, interorganizational interaction both in the context of crisis management and more generally, network analysis, and the development of neo-institutional theory within organizational analysis.

To purchase reprints of this article please e-mail: reprints@emeraldinsight.com Or visit our web site for further details: www.emeraldinsight.com/reprints 